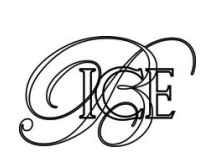

Álvaro Espejo León *

Julia M. Núñez Tabales*

Fernando J. Fuentes García*

\title{
NUEVO ESCENARIO DEL SECTOR DEL VINO ESPAÑOL Perspectivas estratégicas internacionales
}

Mediante este trabajo se pretende analizar la situación actual del sector del vino en España con especial referencia a sus fortalezas y oportunidades en el exterior. Para ello, se aportan y actualizan datos sobre el sector vitivinícola mundial y en especial del español, a la vez que se efectúa un análisis descriptivo de las variables más relevantes (superficie, producción, consumo, exportaciones e importaciones) para extraer conclusiones de la situación actual y futura en los mercados internacionales. Los resultados estadísticos hacen entender parte de las decisiones y perspectivas estratégicas internacionales que actualmente están siendo tomadas por las bodegas españolas. Se identifica que la estrategia internacional tiene dos líneas diferenciadas: apuesta creciente de las bodegas por vender calidad frente a cantidad - por la propia naturaleza del vino español- y la venta a granel en volumen que sirve especialmente para dar salida al producto y ganar liquidez a corto plazo.

Palabras clave: bodegas, comercio exterior, internacionalización, estrategias.

Clasificación JEL: Q17, L16.

\section{Introducción}

Según datos publicados por el Instituto Nacional de Estadística (INE) se ha producido en los últimos años una reducción del número de bodegas españolas debido a dos aspectos fundamentalmente: el primero de ellos radica en el panorama actual de la industria que está caracterizada por un elevado nivel de atomización y un elevado número de bodegas; en segundo lugar, se suma la contracción del consumo interno, motivado por la crisis, por el cambio de tendencias de hábitos de los consumidores

* Profesores del Área de Organización de Empresas. Facultad de Derecho y Ciencias Económicas y Empresariales. Universidad de Córdoba. Versión de junio de 2015. y por la competencia de bebidas alcohólicas sustitutivas (Martín, 2006).

Por consiguiente, el sector del vino español se enfrenta a una difícil situación que obliga a situarse en nuevas realidades y enfrentarse a nuevos problemas que conllevan buscar nuevas soluciones, entre las que se encuentra la salida estratégica a mercados internacionales, que comienza a ser una realidad en los últimos años (Langreo, 2008; Santos, Fuentes y Sánchez, 2009). En ese mercado exterior, los exportadores españoles de vino se encuentran un sector que se desarrolla en un entorno crecientemente competitivo por la entrada de nuevos países productores. Estos están implantando estrategias innovadoras en producción y comercialización y están ocupando crecientes cuotas de $\triangleright$ 


\begin{tabular}{|c|c|c|c|c|c|c|c|c|c|c|}
\hline & & & & SUPERFICI & $\begin{array}{c}\text { TABLA } 1 \\
\text { DE VIÑEDC } \\
\text { (Hectáreas) }\end{array}$ & EN ESPAÑA & & & & \\
\hline 2014 & 2013 & 2012 & 2011 & 2010 & 2009 & 2008 & 2007 & 1980 & $\begin{array}{c}\text { \% Var. } \\
1980 / 2014\end{array}$ & $\begin{array}{c}\% \text { Var. } \\
2013 / 2014\end{array}$ \\
\hline 950.541 & 965.094 & 967.055 & 985.005 & 1.037 .356 & 1.077 .535 & 1.129 .950 & 1.137 .960 & 1.642 .584 & $-42,13$ & $-0,20$ \\
\hline
\end{tabular}

mercados mundiales, así el grupo de nuevos productores -Australia, Chile, Argentina y Sudáfricacopan ya significativos porcentajes de las exportaciones totales. A ello, hay que añadir una mayor apertura al exterior y un aumento de la importancia de las exportaciones como salida de las producciones interiores. A pesar de esto, se identifica cierta consolidación y madurez en los principales mercados, así como la aparición de nuevos mercados, especialmente terceros, que pueden estar motivados especialmente por las ayudas europeas a la promoción en países terceros.

\section{Superficie de viñedo}

España es el país del mundo que más superficie dedica al cultivo de la vid, en extensión ocupa cerca del millón de hectáreas, lo que supone, según datos de la Organización Internacional de la Viña y del Vino (OIV, 2014), el 13,52 por 100 de la superficie mundial y el 29 por 100 de la superficie europea. Dentro de nuestro territorio, las plantaciones se extienden a lo largo del 2,5 por 100 de la superficie, lo que representa el 6,5 por 100 de la superficie cultivada, según datos de noviembre de 2014 de ESYRCE ${ }^{1}$. Hay que resaltar que el viñedo español se dedica preferentemente y casi exclusivamente a la obtención de uva para vinificación. Por ello, a partir de ahora, se va a referir dicho tipo de viñedo y de uva. Además, del total plantado, el 64 por 100 corresponde a secano, que cayó un 1,7 por 100 respecto a 2013, mientras que el área de regadío gana terreno al crecer un 5 por 100. También, es importante destacar que

\footnotetext{
${ }^{1}$ Encuesta sobre Superficies y Rendimientos de los Cultivos de España.
}

España es uno de los países que más cantidad proporcional tiene de viñedo plantado bajo indicación geográfica protegida, con un 85 por 100 del total -frente al 64 por 100 de Francia, el 48 por 100 de Italia o el 63 por 100 de media en la UE-.

En la Tabla 1 se observa, desde 1980, la tendencia a la reducción de la superficie del viñedo español con la reducción de más de un 40 por 100 de su superficie.

Uno de los grandes causantes de esta nueva reestructuración de la superficie en España, al igual que ocurre con la producción, como se expondrá en el siguiente apartado, y de su evolución descendente, es la anexión de España en 1986 al Tratado de Adhesión a la Comunidad Económica Europea (Piqueras, 1997). También, entre las causas puede citarse la entrada en vigor de la nueva Organización Común de Mercados del Vino $\left(\mathrm{OCM}^{2}\right)$, el régimen voluntario de arranques que establece y el bajo precio de la uva ${ }^{3}$. El Reglamento de la Comunidad Económica Europea (CEE) n 1442/88 que se aprobó a finales de la década de los noventa, fue también otro de los alicientes a reducir la superficie. Se han eliminado muchas de las hectáreas que eran poco productivas, quedando indemnes las de alto rendimiento en producción de uva para vinificación. $D$

\footnotetext{
2 Propone alcanzar un mayor equilibrio entre la oferta y la demanda en el mercado comunitario, así como mejorar a largo plazo la competitividad del sector. Gracias a la OCM se ha podido financiar la reestructuración de una parte importante del viñedo para adaptarlo a la oferta y la demanda.

3 Esta información coincide con la opinión y reflexiones de D. Manuel M. López Alejandre (secretario perpetuo del Consejo Regulador de la Denominación de Origen (DO) Montilla-Moriles, enólogo y presidente del aula del vino), quien en una entrevista concertada con motivo de conocer su visión sobre el sector del vino, resaltó como posible causa de esta caída de la superficie, el hecho de que España -al igual que Europa- es excedentaria en este tipo de producto $\mathrm{y}$, por consiguiente, está sobredimensionado el terreno dedicado a este tipo de cultivo. Expone que la situación ideal de superficie en España debería ser de 500.000 has (en 2014 supera las 950 mil has).
} 
NUEVO ESCENARIO DEL SECTOR DEL VINO ESPAÑOL: PERSPECTIVAS ESTRATÉGICAS...

\begin{tabular}{|c|c|c|c|c|c|c|c|c|c|c|c|c|c|}
\hline & & & PRINC & ALES $\mathrm{P}$ & $\begin{array}{l}\text { ÍSES } \\
\text { (En mi }\end{array}$ & $\begin{array}{l}\text { TABL } \\
\text { ODUC } \\
\text { nes de }\end{array}$ & RES M & $\begin{array}{l}\text { NDIAL } \\
\text { s) }\end{array}$ & DE VI & & & & \\
\hline & 2014 & 2013 & 2012 & 2011 & 2010 & 2009 & 2008 & 2007 & 2006 & 2005 & 2004 & $\begin{array}{c}\% \text { Var. } \\
\text { 2004/2014 }\end{array}$ & $\begin{array}{c}\text { \% Var. } \\
2013 / 2014\end{array}$ \\
\hline 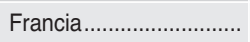 & 46,1 & 42,0 & 41,1 & 50,8 & 44,4 & 46,3 & 45,6 & 52,1 & 52,1 & 52,1 & 57,3 & $-19,55$ & 9,76 \\
\hline Italia ................................ & 44,4 & 44,9 & 43,8 & 42,8 & 48,5 & 47,3 & 48,1 & 49,6 & 52,0 & 50,5 & 49,9 & $-11,02$ & $-1,11$ \\
\hline España.................................. & 41,6 & 42,7 & 31,1 & 33,4 & 35,4 & 36,1 & 36,7 & 38,2 & 38,1 & 37,8 & 42,9 & $-3,03$ & $-2,58$ \\
\hline EEUU ............................... & 22,5 & 22,0 & 20,5 & 19,2 & 20,9 & 22,0 & 19,2 & 20,1 & 19,4 & 22,8 & 20,1 & 11,94 & 2,27 \\
\hline Argentina .......................... & 15,2 & 15,0 & 11,8 & 15,5 & 16,3 & 12,1 & 14,6 & 15,0 & 15,3 & 15,2 & 15,4 & $-1,30$ & 1,33 \\
\hline Australia................................ & 12,5 & 12,5 & 12,3 & 11,2 & 11,4 & 11,8 & 9,6 & 11,2 & 14,2 & 14,3 & 14,6 & $-14,38$ & 0,00 \\
\hline China ............................... & 11,7 & 11,7 & 13,8 & 13,2 & 13,0 & 12,8 & 11,4 & 11,5 & 12,0 & 12,0 & 11,7 & 0,00 & 0,00 \\
\hline 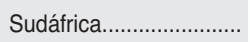 & 11,4 & 11,0 & 10,6 & 9,7 & 9,3 & 10,0 & 10,0 & 9,5 & 9,3 & 8,4 & 9,2 & 23,91 & 3,64 \\
\hline 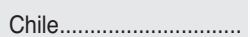 & 10,0 & 12,8 & 12,6 & 10,5 & 8,8 & 10,1 & 8,6 & n.d. & 8,4 & 7,8 & 6,3 & 58,73 & $-21,88$ \\
\hline 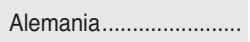 & 9,7 & 8,3 & 9,0 & 9,1 & 6,9 & 9,2 & 10,3 & 9,0 & 8,9 & 9,1 & 10,0 & $-3,00$ & 16,87 \\
\hline Resto ……......................... & 45,5 & 58,1 & 51,6 & 52,1 & 49,6 & 54,6 & 54,5 & 51,3 & 52,9 & 48,0 & 59,0 & $-22,88$ & $-21,69$ \\
\hline Total ................................ & 270,8 & 281,0 & 258,2 & 267,4 & 264,5 & 272,2 & 268,6 & 267,5 & 282,6 & 278,0 & 296,4 & $-8,64$ & $-3,63$ \\
\hline
\end{tabular}

El resultado no fue otro que el de la ya comentada reducción de la superficie destinada al cultivo de la vid, pero sin resentirse en los excedentes de vino.

\section{Producción}

Según las últimas estadísticas publicadas por la OIV y el OEMV (Observatorio Español del Mercado del Vino, 2014) ocuparía el tercer puesto en el ranking de la producción de vino a nivel mundial, por detrás sólo de Francia, que recupera su posición de liderazgo, e Italia. Destaca la recuperación en este último año de Francia, la gran caída de producción en Chile o la estabilidad de las producciones de los grandes productores de vino. $\mathrm{Si}$ se atiende a las variaciones en la última década destacan positivamente los nuevos mercados del vino como Chile (58,73 por 100), Sudáfrica $(23,91$ por 100) y EEUU (11,94 por 100).

En el lado negativo, destacan en la última década variaciones en la las caídas de producción de los dos principales productores (Francia e Italia, 19 y 11 por 100 respectivamente), al igual que países con tradición como Australia. Igualmente, es importante destacar la concentración de la producción de vino, copando los tres primeros países (Francia, Italia y España) cerca de la mitad del vino producido en el mundo, y situándose el 83 por 100 de la producción de vino en manos de 10 países.
En el caso español se han ido manteniendo niveles parecidos en los últimos diez años y se puede decir que mantiene cierta consolidación aunque con una tendencia descendente, conservando el 15 por 100 de la producción mundial de vinos. Del total producido en España, los vinos de mesa suponen un 53 por 100 y los vinos con denominación de origen un 33 por 100. Por colores, 19 millones de hectolitros corresponden a vinos tintos y rosados (56 por 100 del total) y 15 millones (44 por 100 del total) a vinos blancos, según las últimas estadísticas publicadas por la OEMV (2014).

\section{Consumo}

El consumo mundial de vino se mantuvo prácticamente estable en 2013 (último año con datos oficiales publicados), ya que tan solo descendió un 1 por 100 respecto al año anterior hasta situarse en los 238,7 millones de hectolitros (hl), como se puede observar en la Tabla 3, donde se aprecia que EEUU ha superado a Francia como primer consumidor de vino en el mundo. En este sentido, EEUU y Francia absorben casi un 25 por 100 del consumo mundial de vino, y un 50 por 100 del consumo mundial corresponde a los cinco primeros países (EEUU, Francia, Italia, Alemania y China). En EEUU se consumieron 29 millones de hectolitros, con un ligero $\triangle$ 


\begin{tabular}{|c|c|c|c|c|c|c|c|c|c|}
\hline \multicolumn{10}{|c|}{$\begin{array}{c}\text { TABLA } 3 \\
\text { PRINCIPALES POTENCIAS MUNDIALES } \\
\text { (Consumo del vino en millones de hectolitros) }\end{array}$} \\
\hline País & 2013 & 2012 & 2011 & 2010 & 2009 & 2008 & 2007 & 2006 & 2005 \\
\hline EEUU .................... & 29,1 & 29,0 & 28,4 & 27,6 & 27,2 & 28,0 & 27,1 & 19,4 & 27,1 \\
\hline Francia .................... & 28,1 & 30,2 & 29,3 & 29,3 & 29,9 & 31,0 & 32,1 & 33,0 & 33,2 \\
\hline 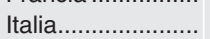 & 21,7 & 22,6 & 23,1 & 24,6 & 24,5 & 26,0 & 26,2 & 27,8 & 27,1 \\
\hline Alemania ............... & 20,3 & 20,0 & 19,7 & 20,2 & 20,2 & 20,2 & 20,3 & 20,1 & 19,8 \\
\hline China ....................... & 16,8 & 17,8 & 16,3 & 15,2 & 14,0 & 14,0 & 14,0 & 14,1 & 13,7 \\
\hline Reino Unido ......... & 12,7 & 12,5 & 12,9 & 12,9 & 12,6 & 14,0 & 13,9 & 12,3 & 12,1 \\
\hline Rusia ......................... & 10,5 & 10,9 & 11,3 & 12,2 & 10,0 & 11,7 & 11,5 & 10,0 & 10,1 \\
\hline Argentina .............. & 10,3 & 10,1 & 9,8 & 9,8 & 10,2 & 11,0 & 10,2 & 10,1 & 10,9 \\
\hline España ................... & 9,1 & 9,3 & 9,9 & 10,9 & 11,2 & 12,0 & 13,0 & 13,8 & 14,2 \\
\hline Australia .................. & 5,2 & 5,4 & 5,3 & 5,4 & 5,0 & 4,4 & 4,5 & 4,6 & 4,6 \\
\hline
\end{tabular}

repunte interanual del 0,5 por 100 , frente al fuerte descenso del 7,4 por 100 que ha sufrido Francia respecto a 2012, situándose en los 28 millones de hl. En tercer lugar se situó Italia, con 21,7 millones de hl, seguido de cerca por Alemania, con 20,3 millones de hl y único país de la Unión Europea que ha mejorado sus cifras, con un repunte de 0,3 millones respecto al año anterior. A pesar de que China no ha facilitado sus datos, desde la OIV se estima un descenso de su nivel de consumo en un 3,8 por 100, apareciendo en quinto lugar.

Otro aspecto que puede percibirse analizando la Tabla 3 junto a la Tabla 2 es la categoría de países excedentarios de vino o demandantes de vino en función de la ratio entre consumo y producción. De esta forma se aprecia que Francia consume aproximadamente el 60 por 100 de lo que produce, Italia produce casi el doble de lo consumido (48 por 100) y en España se produce cinco veces más de lo consumido (21 por 100). Dichos países venden parte de su producción a países deficitarios, tales como EEUU (132 por 100), China (144 por 100) o Reino Unido.

Analizando el caso de España, con 9,1 millones de hl consumidos en 2013, baja hasta el noveno puesto en el ranking de países consumidores de vino, incluso con consumos per cápita muy alejados de los principales mercados. La tendencia a la reducción en el consumo ha sido la nota predominante durante la última década, a pesar de la recuperación obtenida en los años 2003 y 2004. La inestabilidad que vive el sector del vino -como resultado de desajustes entre oferta y demanda, significativas ayudas inyectadas desde algunas instituciones, fuerte competencia en mercados mundiales o preferencia de una parte de la población por otro tipo de bebidasha afectado también a la evolución en el consumo del vino; el cual en España ha bajado en 33 años de los 18 millones de $\mathrm{hl}$ en el año 1982, a apenas 9,1 millones de $\mathrm{hl}$ consumidos en 2013, y pasando de 10,4 litros por persona consumidos en 2007 a 8,7 en 2013. Sin entrar en profundidad en las razones que han motivado este desplome en el consumo de vino, es indudable que la crisis que se padece desde el año 2008 no ha ayudado a frenar la caída, tampoco han contribuido a mitigar las bajas cifras de consumo el endurecimiento de las leyes ligadas al consumo de alcohol, ni los amplísimos márgenes que algunos establecimientos del canal HORECA (hostelería, restauración y catering) siguen imponiendo al precio de los vinos que incluyen en sus cartas, aunque conviene matizar que los márgenes aplicados al resto de bebidas en este canal se encuentran muy por encima que los aplicados al propio vino (Guirao, López, Rodríguez y Romero, 2004; Martín Cerdeña, 2014). En cuanto al consumo de bebidas alcohólicas en España en el año 2013, en base a información obtenida del informe sobre gasto en alimentación realizado por el MAGRAMA ${ }^{4}$ (2015) se observa que la cerveza y el vino son los dos tipos de bebidas alcohólicas más consumidas en España casi por igual (40 por 100), a mucha diferencia se encuentran otras bebidas como el whisky, la ginebra y el ron.

\footnotetext{
${ }^{4}$ Ministerio de Agricultura, Alimentación y Medio Ambiente.
} 
NUEVO ESCENARIO DEL SECTOR DEL VINO ESPAÑOL: PERSPECTIVAS ESTRATÉGICAS...

\begin{tabular}{|c|c|c|c|c|c|c|c|c|c|c|}
\hline \multicolumn{11}{|c|}{$\begin{array}{l}\text { TABLA } 4 \\
\text { PRINCIPALES EXPORTADORES MUNDIALES DE VINO POR PAÍSES } \\
\text { (Miles de euros) }\end{array}$} \\
\hline & 2014 & 2013 & 2012 & 2011 & 2010 & 2009 & 2008 & 2007 & $\begin{array}{c}\% \text { Var. } \\
2007 / 2014\end{array}$ & $\begin{array}{c}\% \text { Var. } \\
2013 / 2014\end{array}$ \\
\hline Mundo....... & 26.031 .805 & 25.998 .493 & 25.683 .068 & 23.528.106 & 21.015 .791 & 18.386.986 & 20.322 .860 & 20.084 .576 & 29,61 & 0,13 \\
\hline Francia ...... & 7.720 .379 & 7.861 .285 & 7.832 .383 & 7.161.232 & 6.316 .783 & 5.514 .590 & 6.837 .859 & 6.769 .716 & 14,04 & $-1,79$ \\
\hline Italia ............... & 5.104 .968 & 5.041 .482 & 4.695 .252 & 4.402 .197 & 3.915 .500 & 3.523 .699 & 3.665 .065 & 3.543 .499 & 44,07 & 1,26 \\
\hline España ...... & 2.558 .854 & 2.582 .323 & 2.566 .345 & 2.217.712 & 1.879 .057 & 1.897 .086 & 1.962 .054 & 1.820 .250 & 40,58 & $-0,91$ \\
\hline Chile ........... & 1.396 .269 & 1.422 .907 & 1.398 .097 & 1.217 .833 & 1.165 .192 & 990.280 & 936.407 & 917.596 & 52,17 & $-1,87$ \\
\hline Australia ... & 1.261 .607 & 1.339 .711 & 1.522 .298 & 1.425 .592 & 1.437 .767 & 1.292 .347 & 1.436 .021 & 1.795 .891 & $-29,75$ & $-5,83$ \\
\hline EEUU ........ & 1.104 .466 & 1.174 .084 & 1.076 .419 & 965.364 & 831.639 & 629.998 & 655.688 & 660.057 & 67,33 & $-5,93$ \\
\hline Alemania .. & 975.732 & 1.013 .240 & 975.190 & 976.811 & 858.705 & 733.415 & 764.739 & 725.923 & 34,41 & $-3,70$ \\
\hline
\end{tabular}

\section{Comercio exterior del vino español}

\subsection{Exportaciones de vino}

Las exportaciones mundiales de vino presentan una tendencia creciente en materia de exportación (29 por 100), lo que demuestra que es un artículo con un gran potencial y una gran importancia en los mercados. Entre las causas de este crecimiento se encuentra la irrupción de este producto en mercados nuevos y con un gran mercado potencial en cuanto a número de habitantes, tales como China, Japón o EEUU. Igualmente, es necesario resaltar la importancia que van alcanzando los vinos chilenos, argentinos y australianos (Tabla 4) que se caracterizan por poseer una excelente relación calidad/precio, razón por la que ganan muchos clientes en aquellos países con poca tradición vitivinícola y cuyas exigencias son menores.

Francia es el país que más vino exporta en valor (7,7 millardos de euros), seguido de Italia y España (5,1 y 2,5 millardos de euros respectivamente). Otro dato destacado hace referencia al porcentaje que los tres principales países (Italia, España y Francia) poseen con respecto a las exportaciones totales de vino, siendo este de un 58 por 100. Asimismo concentran cerca de un 67 por 100 de las exportaciones respecto a los 10 principales países exportadores analizados. Otros países que destacan por sus importantes subidas en las exportaciones a otros mercados en los últimos años son Chile o EEUU. De los 10 principales países exportadores de vino todos han mostrado un comportamiento positivo en el periodo de estudio, siendo tan solo Australia la que ha visto reducidas sus exportaciones.

En cuanto a España, durante las últimas décadas, ha cambiado de manera significativa su distribución geográfica y su estructura, ampliando el abanico de destinos de venta de sus vinos. España se convirtió en el líder mundial de las exportaciones por volumen en 2014 alcanzando 22,6 millones de hl, un 22,3 por 100 más que el año anterior, superando así a Italia, gracias a la excepcional cosecha del año anterior donde se vendieron los vinos más económicos. En valor, aunque aún no es líder ya que Francia e Italia le superan, se mantienen los datos alcanzando los 2.582 millones de euros. Se interrumpe así una tendencia donde se ampliaba la diferencia entre las ventas en valor con las de volumen (Gráfico 1), también es cierto que dicha senda es atribuible a lo extraordinario de la cosecha de 2013 como se ha mencionado anteriormente, donde hubo excedente de vino y se vendió a un precio inferior. A pesar de esto, aunque España en 20 años ha multiplicado por tres sus ventas de vino en el exterior, el precio medio de 2014 solo supera en un céntimo al de aquella fecha. Es importante resaltar que según datos de ESTACOM (2014), de los 22,6 millones de hl exportados por España, los envasados suponían 7,4 millones de hl (con un crecimiento del 5,3 por 100 en volumen pero solo del 0,8 por 100 en valor), 12,6 millones de hl (el 55 por 100) a granel siendo su principal destino Francia, a un precio medio de solo 0,40 euros/litro, frente $\triangle$ 
GRÁFICO 1

EXPORTACIONES ESPAÑOLAS DE VINO POR VOLUMEN Y POR VALOR

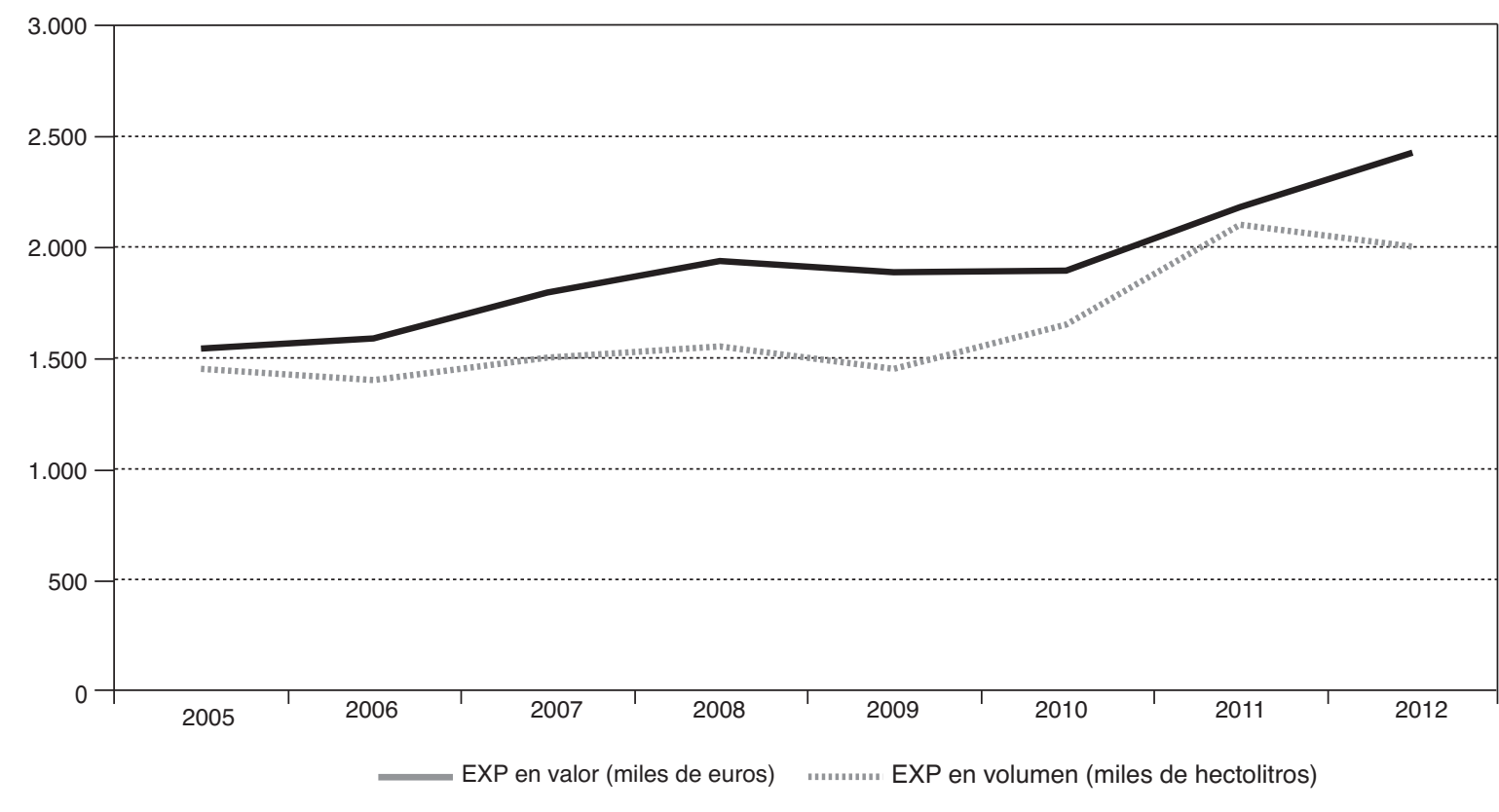

Fuente: elaboración propia a partir de ESTACOM.

a los 0,60 del año anterior, lo que evidencia que el problema de rentabilidad del vino español, en el año 2014, ha estado directamente vinculado con el bajo precio al que vende sus caldos. Los vinos a granel han constituido la salida para eliminar excedentes, pero están convirtiéndose en un lastre para un sector que ve mermada su rentabilidad.

Los precios medios mundiales del vino en 2014 se situaron en 2,46 euros/litro. Como se puede observar en el Gráfico 2, los vinos franceses, sin embargo, alcanzan una media de 5,37 euros/litro; seguidos de los neozelandeses, a 4,36 euros/litro, los estadounidenses a 2,73 euros/litro; y los portugueses, a 2,55 euros/litro. Para encontrar los vinos españoles en ese ranking de precios por litro hay que bajar al puesto 11, el último lugar en el conjunto de los grandes países exportadores, con una media de 1,1 euros/litro, lo que supone un descenso del 22 por 100 sobre los 1,43 euros de la campaña anterior. Así, Francia -país que más valor da a sus litros de vino- los vende en mercados exteriores a un precio casi cinco veces superior al de los españoles.
Por esto las conclusiones del sector español tienen una doble versión: suben las unidades vendidas, pero bajan los ingresos por vender el producto a un precio inferior. Es cierto que este comportamiento ocurrido en 2014 se ha debido a una cosecha excepcional que hizo vender más y a precios más bajos, y cortó una racha positiva donde se estaba ampliando el valor de las exportaciones por encima del volumen, aunque no cabe duda que habrá que estar atentos a la tendencia en los próximos años.

En cuanto al destino de los vinos españoles, principalmente tiene lugar a países de la Unión Europea, aunque es importante destacar que las exportaciones se encuentran diversificadas, ya que aunque los diez principales países destino de las exportaciones representan el 70 por 100 de las exportaciones totales, actualmente se exporta a 188 destinos de todo el mundo según informaciones recogidas en ESTACOM ${ }^{5}$ y las bodegas empiezan a extenderse muy particularmente fuera de la Unión Europea.

${ }^{5}$ Servicio estadístico de Instituto de Comercio Exterior e Inversiones español (ICEX) de base de datos sobre las exportaciones e importaciones españolas. 
NUEVO ESCENARIO DEL SECTOR DEL VINO ESPAÑOL: PERSPECTIVAS ESTRATÉGICAS...

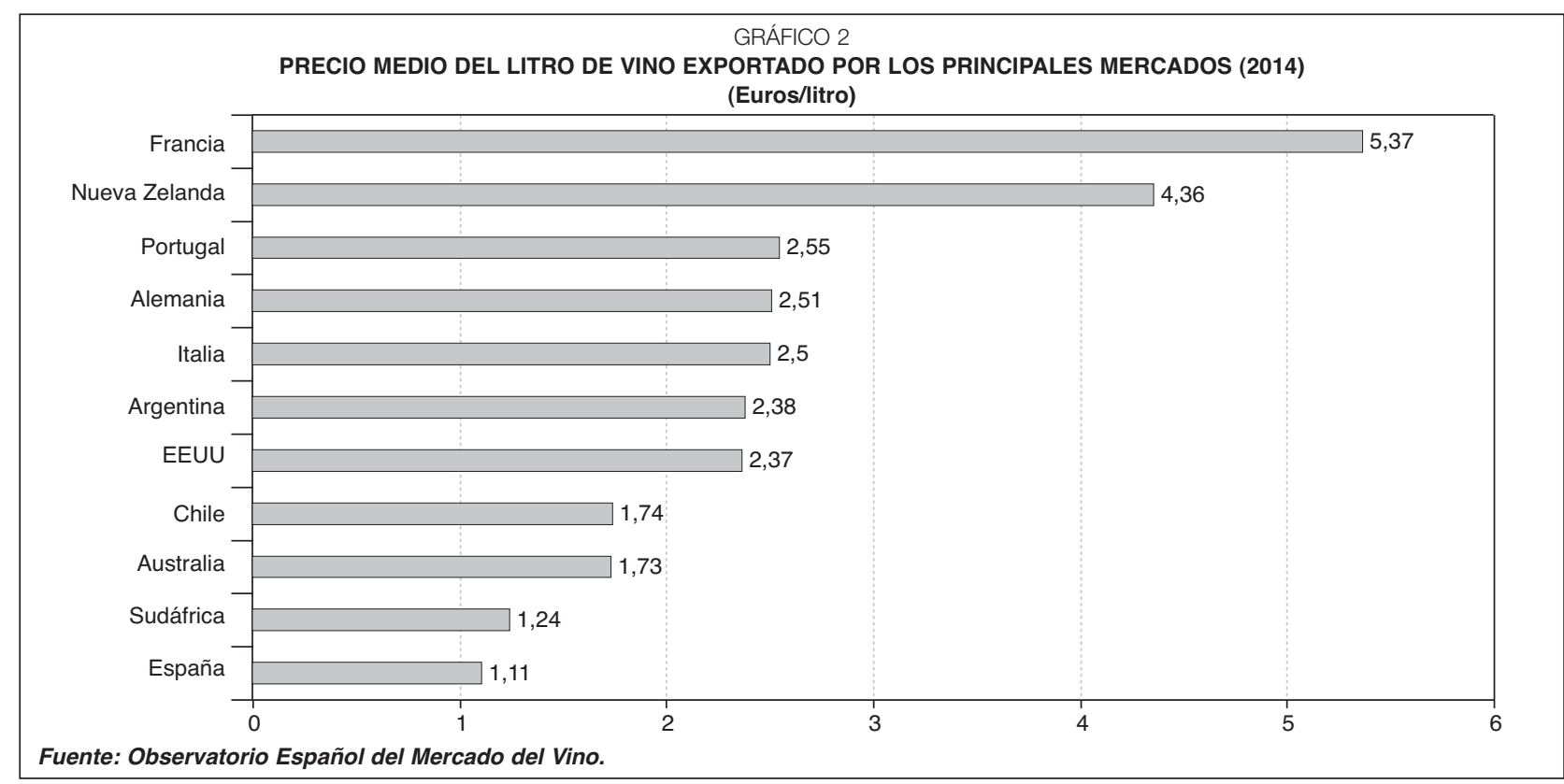

\begin{tabular}{|c|c|c|c|c|c|c|c|c|c|c|}
\hline \multicolumn{11}{|c|}{$\begin{array}{l}\text { TABLA } 5 \\
\text { EXPORTACIONES ESPAÑOLAS MUNDIALES DE VINO POR PAÍSES } \\
\text { (Millones de euros) }\end{array}$} \\
\hline & 2014 & 2013 & 2012 & 2011 & 2010 & 2009 & 2008 & 2007 & $\begin{array}{c}\% \text { Var } \\
2007 / 2014\end{array}$ & $\begin{array}{c}\% \text { Var } \\
2013 / 2014\end{array}$ \\
\hline Alemania ......................... & 367,26 & 405,44 & 362,98 & 336,56 & 308,05 & 287,84 & 337,38 & 290,71 & 26,33 & $-9,42$ \\
\hline Reino Unido ......................... & 339,12 & 344,70 & 332,94 & 309,37 & 299,64 & 271,41 & 283,05 & 305,58 & 10,98 & $-1,62$ \\
\hline 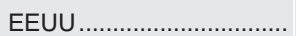 & 248,63 & 246,30 & 242,05 & 213,03 & 200,64 & 173,94 & 183,48 & 195,97 & 26,87 & 0,95 \\
\hline 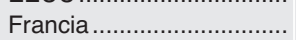 & 233,33 & 252,33 & 206,70 & 172,39 & 128,32 & 319,94 & 141,99 & 114,75 & 103,34 & $-7,53$ \\
\hline 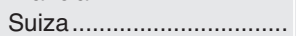 & 113,32 & 110,13 & 107,42 & 101,47 & 103,37 & 100,46 & 98,73 & 98,19 & 15,41 & 2,90 \\
\hline Países Bajos ........................ & 105,99 & 98,14 & 87,00 & 87,75 & 78,66 & 75,94 & 79,42 & 74,72 & 41,85 & 8,00 \\
\hline Bélgica ………………..... & 105,34 & 96,70 & 87,16 & 77,91 & 73,10 & 71,17 & 59,58 & 50,23 & 109,72 & 8,93 \\
\hline 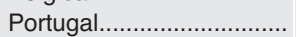 & 89,31 & 88,58 & 60,25 & 51,43 & 59,57 & 67,76 & 61,08 & 43,45 & 105,55 & 0,82 \\
\hline China & 83,46 & 73,96 & 90,59 & 70,27 & 38,02 & 14,11 & 13,89 & 9,95 & 738,79 & 12,84 \\
\hline 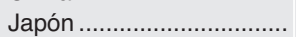 & 78,13 & 120,99 & 80,90 & 58,17 & 51,85 & 45,51 & 49,34 & 36,62 & 113,35 & $-35,42$ \\
\hline Resto.................................... & $1.765,88$ & $1.836,27$ & $1.658,56$ & $1.478,35$ & $1.341,21$ & $1.428,08$ & $1.307,94$ & $1.220,17$ & 44,72 & $-3,83$ \\
\hline Total & $2.517,72$ & $2.596,84$ & $2.424,35$ & $2.178,89$ & $1.893,50$ & $1.884,18$ & $1.934,94$ & $1.793,35$ & 40,39 & $-3,05$ \\
\hline
\end{tabular}

Las ayudas a la internacionalización de nuestros vinos y, especialmente las ayudas europeas a la promoción en países terceros ${ }^{6}$, parecen estar detrás de esta renovada expansión del vino español hacia nuevos destinos. EEUU y China emergen como dos de los destinos más destacados en los últimos años y donde mayores esfuerzos comerciales realizan nuestras bodegas. Con todo esto, Alemania es el principal destino de las exportaciones españolas de vinos por valor, con unas ventas hacia este país de 367 millones de euros, suponiendo el 16 por 100 del total de ventas

\footnotetext{
6 Ayudas OCM con fondos FEDER de la Unión Europea.
}

españolas. Le sigue Reino Unido con una cuota del 13 por 100, y con unas ventas de 340 millones de euros. Tras estos dos países se encuentran, con una cuota del cerca del 10 por 100, tanto EEUU como Francia. Cabe resaltar especialmente el caso francés, con un aumento en sus compras de vinos españoles del 100 por 100 en los últimos 8 años, frente al 26 por 100 del estadounidense, que tienen como destino la mezcla con vino francés y/o el embotellado con marcas francesas. Las exportaciones a Países Bajos se encuentran en $6^{a}$ posición, con tasas positivas de aumento en el periodo estudiado. Por comunidades autónomas, en cuanto a exportaciones en valor, Castilla-La Mancha (23 por $100 \triangleright$ 
del total exportado de vinos españoles) se coloca al frente de las regiones más exportadoras, seguida de Cataluña (22 por 100 sobre el total), La Rioja y el País Vasco.

\subsection{Importaciones de vino}

En lo referente a las importaciones, España queda fuera del top 10 de los principales países importadores de vino. Este dato es lógico si atendemos a que España es una de las grandes potencias exportadoras en este mercado. Las adquisiciones de Champagne francés son el principal componente de las importaciones de vinos en nuestro país. En términos de volumen, las importaciones apenas alcanzaron los 1,6 millones de $\mathrm{hl}$, cantidad muy reducida en comparación con el dato de sus exportaciones (18 millones de hl). En cuanto a los principales proveedores, a parte del ya citado Champagne francés, estaría el Lambrusco italiano (Vinetur, 2013).

\section{Fortalezas del sector español y oportunidades en el exterior}

Entre las fortalezas del sector del vino español se encuentra, sin lugar a dudas, la extraordinaria calidad de los caldos españoles. De hecho, muchos de los compradores internacionales, críticos y revistas de prestigio reconocen la excelente calidad del vino español. En este sentido podemos citar como ejemplo el hecho de que Robert Parker ${ }^{7}$ haya tomado la decisión de que Jay Miller (mano derecha del anterior) visite España varias veces al año para catar y puntuar los vinos españoles en las regiones donde se producen. Esto supone un reconocimiento al potencial de España ya que esto solo lo hace la publicación Wine Advocate ${ }^{8}$ con regiones

\footnotetext{
7 Referente más importante del mundo entre los profesionales del vino.

8 Revista dirigida por Robert Parker, en la que escribe sobre los principales vinos y tiene una alta repercusión mediática a nivel mundial dentro del sector.
}

tan reconocidas como Burdeos, California o Ródano, entre otras.

Asimismo, España cuenta con una producción de vinos en cantidad suficiente como para tener un impacto global. Como se ha mencionado con anterioridad, este país posee la extensión de superficie de viñedo más grande del mundo y cuenta con una enorme diversidad de estilos y de varietales autóctonos, lo cual aporta relevancia día tras día en los mercados exteriores, ya que muchos consumidores internacionales comienzan a buscar nuevas regiones y uvas diferentes.

Igualmente, se identifica un extraordinario impulso exportador fruto de la combinación de tres factores: por un lado, una mentalidad empresarial consciente de la importancia de los mercados exteriores para nuestro vino; por otro lado, una revolución en las producciones, calidades y equipamientos técnicos que han favorecido la mejora sustancial de la calidad de los productos y la posibilidad de ajustar unos precios competitivos en el mercado; el tercer factor del impulso exportador es un mayor tamaño de las bodegas que ha permitido destinar recursos a la internacionalización progresiva de las bodegas españolas. Mentalidad y recursos, unido a calidades adecuadas a los nuevos consumidores que deben afrontarse, son las claves que explican esta mejora exportadora (Fernández, 2013).

Por lo tanto, es evidente que la exportación se presente como una salida estratégica clave de las bodegas españolas ante la caída del consumo interno (Gráfico 3).

En cuanto a las oportunidades en mercados exteriores ha de mencionarse la evolución positiva del consumo del vino español en Asia y EEUU. El consumo en EEUU ha aumentado un 6 por 100 en 2014, a pesar de la crisis, y un 25 por 100 en China. En EEUU el consumidor busca en estos momentos una mejor relación precio-calidad y la percepción que tienen los americanos es que España es el país que mejor ofrece esa relación (Gallego, 2014). No obstante, el consumidor americano, por su mentalidad, volverá a interesarse por $\triangleright$ 


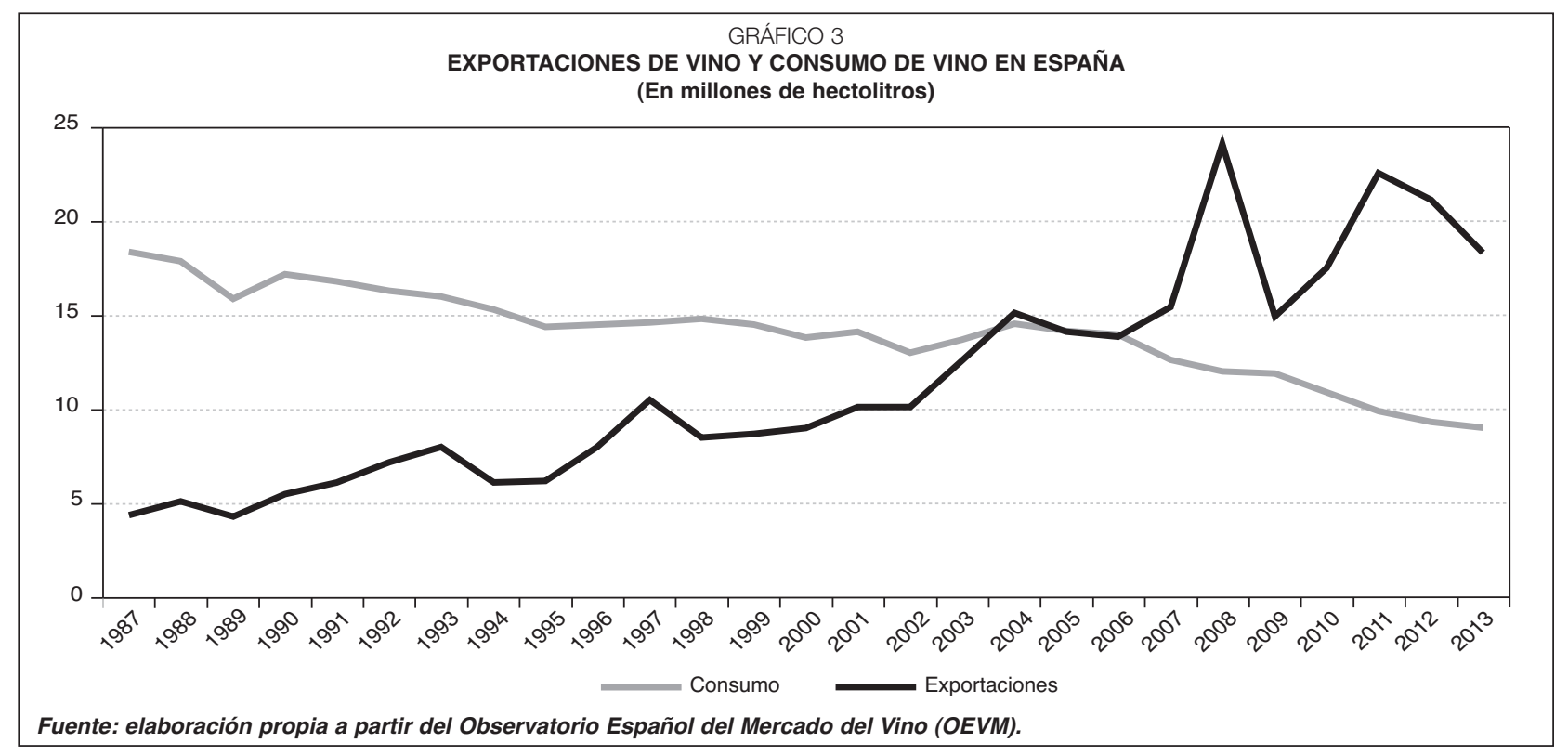

vinos de más alta gama, por lo que ahora es el momento idóneo para introducirse en este mercado. Asia, especialmente en Hong Kong, es el único lugar del planeta donde los vinos premium siguen teniendo éxito a pesar de la situación de la economía internacional. Aunque, por ahora, el interés se centra especialmente en los vinos de culto franceses, los asiáticos (como Corea del Sur, Singapur y China) ya empiezan a descubrir vinos de calidad procedentes de otros países.

\section{Conclusiones}

El vino español se encuentra con una demanda interior que solo es la cuarta parte de la producción, por lo que vender fuera es una necesidad, más que una opción, para mantener los viñedos y la actividad de más de 2.000 bodegas que operan en el exterior. El problema sin resolver es la existencia en el sector del vino español de dos mundos paralelos: uno de ellos está destinado a los vinos de gran calidad y precios elevados, que se mantiene en mercados tradicionales y abre cada año nuevos horizontes; y otro mundo, formado por cientos de cooperativas y bodegas, que se sostiene con la venta de producto a granel y que, gracias a precios bajos, aumentan con fuerza sus ventas en terceros países y tapan los agujeros de otros países que sufren malas campañas. Los datos de 2014 no hacen sino poner en evidencia la necesidad de trabajar en el alto posicionamiento en los mercados mundiales de los vinos de mayor calidad, y avanzar en la generación de valor añadido al producto, envasándolo con marca propia. A continuación se exponen algunas estrategias comerciales sugeridas a las empresas bodegueras españolas.

- La diversificación de cartera, la posibilidad de disponer de una cartera de productos más amplia para acceder a más nichos de mercado y a segmentos desatendidos.

- Buscar la consolidación o activación de las ventas al extranjero, que permita abrir nuevos mercados y nuevos clientes potenciales, y la internacionalización buscando tener cierta presencia en el mercado, ya bien sea productiva, comercial o logística y con la búsqueda de socios locales.

- Apostar por acciones de promoción en destino mostrando los vinos españoles por medio de misiones comerciales directas, visita a ferias o realización de showcooking o catas dirigidas de producto. Igualmente, se aconseja realizar acciones de promoción inversas, es decir, invitar a potenciales compradores y/o prescriptores a visitar las bodegas españolas y conocer la superficie donde se cultiva, el proceso productivo y la cultura de vino propia de la zona. $\square$ 
- Reinvertir beneficios en innovación, tanto en procesos productivos para mejorar la calidad de los caldos o la eficiencia en su producción, como en la comercialización del mismo o la presentación. El alto grado de internacionalización del vino hace que haya una continua adaptación a los muy diversos consumidores, ya que un vino con éxito en un mercado puede no tenerlo en otro, lo que incentiva a innovar para que los productos se adapten a los distintos mercados, pero también a los segmentos de un mismo mercado. Probablemente las innovaciones más trascendentales han sucedido en la enología, por su rápida incorporación y trascendencia para la creación de nuevos vinos, la posibilidad de crear productos de gran valor añadido incita a que la innovación sea constante. Igualmente, se recomienda apostar por la inversión en marketing, en aspectos como un packaging atractivo del producto para buscar la atención de los consumidores en un sector tan competitivo. El sector del vino está muy fragmentado y se caracteriza por multitud de pymes, cuya dimensión condiciona la introducción de innovaciones sustanciales. Ante esto se hace imprescindible ayuda tecnológica y profesional que proviene del sector público. Igualmente, las universidades junto con los centros de investigación y los centros tecnológicos deben jugar un papel importante, ya que son los principales generadores de investigación (Albisu, 2014).

- Atender las nuevas tendencias de los mercados y la identificación de nichos. Para ello es importante realizar una labor previa de investigación de mercados para identificar estas tendencias y nuevos nichos. Así, tendencias como el vino ecológico -donde en mercados como el centroeuropeo se demanda y el precio no es una barrera debido a que este concepto lo tienen más interiorizado que en otros mercados- constituye una oportunidad. Otra alternativa es llegar a segmentos premium donde la calidad de los caldos españoles sea identificada, por lo que los esfuerzos se deben centrar en la mejora del servicio y de la presentación (packaging) del mismo, para así poder justificar mayores precios y un mayor valor añadido.

- El uso de las nuevas tecnologías. Las nuevas herramientas surgidas de las tecnologías de la información y la comunicación, especialmente Internet que se ha convertido en un poderoso instrumento para acercar las bodegas a los consumidores, generan ideas nuevas y oportunidades sobre cómo operar y competir en un nuevo entorno de marketing (Mollá, 2007). El desarrollo de la web 2.0 ha dado una dimensión más a este instrumento. Miles de blogs de prescriptores y redes sociales reúnen a personas relacionadas con el mundo del vino. Estas nuevas plataformas ayudan a fortalecer las antiguas -webs corporativas, páginas de ventas o comunicación por email- y mejorar las ventas online. Asimismo, estamos ante canales de comunicación más ágiles y rápidos que mejoran la toma de decisiones y suponen un contacto más directo con el consumidor. Se realiza de esta forma una comunicación más efectiva al tratarse de opiniones vertidas por los propios consumidores. De igual forma, es una vía para mejorar los números en el segmento de los jóvenes, al ser un medio usado y preferido por este colectivo.

- Por último, se propone un relanzamiento del producto y campañas de promoción, reforzando aspectos ligados al vino como su tradición cultural, su valor social, la imagen de estatus y prestigio del producto, la relación con el respeto al medio ambiente o los beneficios saludables. Además, podría resultar de interés para el sector seguir fortaleciendo la salida al exterior bajo una misma marca con prestigio como es la marca «España», incluso buscando relacionar la trilogía cultura-turismo-alimentación, ya que queda demostrado el éxito comercial que lleva una buena gestión de la marca de un país con aumento de relaciones bilaterales (Kilduff y Núñez, 2014). Otros países como Italia utilizan esta estrategia que les dota de mayor fortaleza para ser más competitivos en mercados internacionales.

\section{Bibliografía}

[1] ALBISU, M. (2014). «Reflexiones en torno a la dinámica innovadora del sector del vino», Cuadernos de estudios agroalimentarios, septiembre, pp. 141-152. 
[2] ESYRCE (2014). «Encuesta sobre superficies y rendimientos de los cultivos de España», Boletín Anual del Ministerio de Agricultura, Alimentación y Medio Ambiente del Gobierno de España. Disponible en:

http://www.magrama.gob.es/es/estadistica/ temas/estadisticas-agrarias/boletin2014_tcm7384110.pdf (recuperado el 7 de junio de 2015).

[3] FEDERACIÓN ESPAÑOLA DEL VINO (2014). «Memoria actividades 2014». Disponible en: http://www.fev.es/v_portal/informacion/informa cionver. . sp ?cod $=958 \&$ te $=36 \&$ idage $=1114 \&$ vap $=0 \& n p a g=1$ (rcuperado el 27 de mayo de 2015).

[4] FERNÁNDEZ, C. (2013). «Rafael del Rey, director OeMv: Nuestro objetivo es elevar el precio medio del vino en exportación», publicado el 16/09/2013 en Vinetur. Disponible en:

https://www. vinetur.com/2013091613349/rafaeldel-rey-director-oemv-nuestro-objetivo-es-elevarel-precio-medio-del-vino-en-exportacion.html [Recuperado el 15 junio 2015]).

[5] GALLEGO, L. (2014): El mercado del vino en Estados Unidos, ICEX España Exportación e Inversiones, Nueva York.

[6] GUIRAO, G.; CANO, V.; LÓPEZ, M.; RODRÍGUEZ, M. y ROMERO, M. (2004). Relación entre la frecuencia de consumo de vino y algunas características socioeconómicas de los individuos, Departamento de Economía de las Instituciones, Estadística Económica y Econometría, Universidad de la Laguna.

[7] INSTITUTO COMERCIO EXTERIOR E INVERSIONES DE ESPAÑA (2015). Estadísticas de Comercio Exterior ESTACOM. Disponible en:

http://estacom.icex.es/estacom/desglose.html [Recuperado el 13 de junio de 2015].

[8] INSTITUTO NACIONALDE ESTADÍSTICA(2015). Disponible en:

http://www.ine.es/dynt3/inebase/es/index.htm? padre $=51 \& d h=1$ [Recuperado el 25 de junio de 2015].

[9] INTRACEN (2015). Disponible en: http://www.trademap.org/Index.aspx [Recuperado el 16 de junio de 2015].

[10] KILDUFF, K y NÚÑEZ, J. (2014). «Midiendo el éxito en la gestión de la imagen de un país: estudio de un caso», Boletín Económico de ICE, $\mathrm{n}^{\circ} 3050$, pp.59-68.

[11] LANGREO, L. (2008). «Análisis del sector vitivinícola español», Revista La Tierra Cuadernos, $\mathrm{n}^{\circ}$ 24, pp. 8-18.
[12] MARTíN CERDEÑA, V. (2014). «Consumo de alimentos y bebidas en España: datos recientes y tendencias en hogares, hostelería y restauración», Revista Distribución y Consumo, vol. 2, pp 5-11.

[13] MERCADOS DEL VINO (2015). Disponible en: www.mercadosdelvino.com

[14] MINISTERIODEAGRICULTURA, ALIMENTACIÓN Y MEDIO AMBIENTE (2015). Presentación de los datos de consumo alimentario en el hogar y fuera del hogar en España 2013. Disponible en: http://www.magrama.gob.es/es/alimentacion/ temas/consumo-y-comercializacion-y-distribucionalimentaria/informeconsumoalimentacion 2014_tcm7-382148.pdf

[15] MINISTERIO DE MEDIO AMBIENTE (2014). Estadísticas. Disponible en:

http://www.mma.es/portal/secciones/info_esta distica_ambiental/estadisticas_info/estadisti cas_sectoriales.htm [Recuperado el 15 de mayo de 2015].

[16] MOLLÁ, A (2007). «El marketing y la comercialización de productos agroalimentarios». Mediterráneo económico, $\mathrm{n}^{\circ} 11$, (Ejemplar dedicado a: Nuevos enfoques del marketing y la creación de valor. Coordinado por María Jesús Yagüe), pp. 339-352.

[17] ORGANIZACIÓN INTERNACIONAL DE LA VIÑA Y EL VINO (2015). Disponible en: http://www.oiv.int/oiv/info/esstatoivextracts2/Publica ciones OIV: http://www.oiv.int/oiv/info/esplubica tionoiv [Recuperado el 16 de junio de 2015].

[18] OBSERVATORIO ESPAÑOL DEL MERCADO DEL VINO (2015). Disponible en:

http://www.oemv.es/esp/estadisticas-3p.php (Recuperado el 13 de junio de 2015).

[19] PIQUERAS, J. (1997). «La exportación del vino de España. Los efectos de la integración en la Unión Europea», Cuadernos de Geografía, n 61, pp. 117-143.

[20] SANTOS, L.; FUENTES, F. y SÁNCHEZ, S. (2009). "Comercio exterior de vinos andaluces de calidad evolución y perspectivas», Boletín Económico ICE, $\mathrm{n}^{\circ}$ 2978, pp. 39-50.

[21] VINETUR (2013). Las importaciones de vino en España crecen un 112,7 por 100 en volumen, publicado el 28/05/2013. Disponible en: https://www. vinetur.com/2013052812466/lasimportaciones-de-vino-en-espana-crecen-un1127-en-volumen.htm/ [Recuperado el 23 de junio de 2015].

[22] WINE INSITUTE (2015). Disponible en: http://www.wineinstitute.org/resources/statistics 
